\title{
Sampling of Bemisia tabaci adults using a pre-programmed autonomous pest control robot
}

\author{
Bu-Keun Chung ${ }^{\mathrm{a}}$, Chunlei Xia ${ }^{\mathrm{b}, \mathrm{c}, * *}$, Yoo-Han Song ${ }^{\mathrm{d}}$, Jang-Myung Lee ${ }^{\mathrm{c}}$, Yan Li ${ }^{\mathrm{c}}$, Hungsoo Kim ${ }^{\mathrm{e}}$, Tae-Soo Chon ${ }^{\mathrm{e}, *}$ \\ a Division of Plant Environment, Gyeongsangnam-Do Agricultural Research and Extension Services, Jinju, Republic of Korea \\ b The Research Center of Coastal Environmental Engineering and Technology of Shandong Province, Yantai Institute of Coastal Zone Research, Chinese Academy of Sciences, Yantai, China \\ c School of Electrical Engineering, Pusan National University, Busan, Republic of Korea \\ d Department of Applied Biological and Environmental Science, Gyeongsang National University, Jinju, Republic of Korea \\ e Department of Biological Sciences, College of Natural Science, Pusan National University, Busan, Republic of Korea
}

\section{A R T I C L E I N F O}

\section{Article history:}

Received 13 July 2011

Revised 9 January 2014

Accepted 20 June 2014

Available online 27 June 2014

\section{Keywords:}

Paprika

Greenhouse

Pattern recognition

Sticky trap

Automatic sampling

Low population size

\begin{abstract}
A B S T R A C T
An autonomous robot (Cabbot) was built to control insect pests in a plastic greenhouse and utilized to sample adult whiteflies (Bemisia tabaci) on paprika plants (Capsicum annum var. angulosum). To accomplish this, a sampling device consisting of an air compressor for pest agitation, a sticky trap $(100 \mathrm{~mm} \times 150 \mathrm{~mm})$ and an image processing system for pest identification were installed on the Cabbot. The sampling precision of the Cabbot $(D=0.16)$ was higher than that of the sticky trap $(D=0.19)$ when sampling of adult white flies was conducted in caged pots. The Cabbot could also collect a substantial number of individuals within a short duration (3 minutes). The collection efficiency (i.e., percent of samples collected at least $n$ ( 1 in this case) individuals to the total sample number) of insects by the Cabbot was markedly high at low population size, showing approximately $30 \%$ when the population size was $\leq 16$ individuals per plant. The sampling precision and collection efficiency suggested that the Cabbot is effective in local, short-term sampling and could be used for early warning of pest occurrences.

(C) 2014 Korean Society of Applied Entomology, Taiwan Entomological Society and Malaysian Plant Protection Society. Published by Elsevier B.V. All rights reserved.
\end{abstract}

\section{Introduction}

One of the major obstacles to crop cultivation is pest control including insects, diseases and weeds. Considering the strong potential for pest population outbreaks, a certain level of chemical control is still inevitable; although minimization of chemical spray is emphasized, farmers eventually need to rely on chemical sprays as the final option during the period of cultivation. As is well known, however, the chemical control causes various side-effects, including toxicity in humans and livestock, toxic residues in environment, and pest resistance to chemicals. Accordingly, development of automatic agricultural practice systems is required to minimize chemical sprays while achieving maximum control effects, especially for large scale cultivation in greenhouses.

Slaughter et al. (2008) proposed a general purpose autonomous robotic system for in-row weed control, allowing precise guidance for detection and identification of weeds. Robotics has been further applied to insect pest control, including pest recognition (Zhu and Zhang, 2011)

\footnotetext{
* Corresponding author. Tel.: +8251510 2261.

** Correspondence to: C. Xia, The Research Center for Coastal Environmental Engineering and Technology of Shandong Province, Yantai Institute of Coastal Zone Research, Chinese Academy of Sciences, Yantai 264003, P.R. China. Tel: + 865352109129.

E-mail addresses: c.xia2009@gmail.com (C. Xia), tschon@pusan.ac.kr (T.-S. Chon).
}

and pest counting (Arbogast et al., 2000). Such autonomous robots could accordingly record positions of pest occurrence, spray chemicals to pests, and evaluate control efforts. The sampling efficiency was also investigated by automatically evaluating population densities (Flinn et al., 2009). Sammons et al. (2005) developed a large scale spray robot suitable for spraying pesticides on paprika plants while moving around inside the greenhouse.

The image recognition is a prerequisite for estimation and control of pests. For weeds and pests, vision based methods have been applied to recognition of agricultural objects especially for fruit detection. Brosnan and Sun (2002) presented an automatic fruit recognition method followed by a tomato recognition system for harvesting (Yang et al., 2007). Xia et al. (2013) reported a method for detecting individual plant leaves for micro-spray by automatic machines. Additionally, fruit and leaf picking methods in greenhouses were proposed by Kitamura and Oka (2005), Ota et al. (2007) and van Henten et al. (2003). However, pest recognition in greenhouse conditions has not been extensively reported in previous studies. Furthermore, autonomous sampling by robot has not been studied, especially regarding recognition of small insect pests such as whiteflies. In this study, an autonomous robot was built to perform sample collection, pest recognition and density estimation in a sequence. We report collection efficiency and sampling precision by the robot across different densities of whiteflies in greenhouse. 


\section{Materials and methods}

\section{Construction of greenhouse robot}

An autonomous robot in greenhouse (Cabbot) that operates along the rail installed at the top area of the greenhouse (a hanging type similar to a cable car) was developed to conduct: 1) sampling, 2) pest recognition, and 3) chemical spraying (Fig. 1a). The robot could identify pests such as adult whiteflies on plants (e.g., paprika), record the spatial distribution of pests in the greenhouse, and automatically spray pesticides. The Cabbot was equipped with a driving system, a 3-degree of freedom (3-DOF) arm, an ultra-low volume (ULV) nozzle, touch panel, control system, and automatic sampling device (Fig. 1a). The robot driving system included a motor ( $2 \mathrm{KW}$ ) and wheels matching the size of an "I" beam rail to enable locomotion along the rail in the greenhouse, with navigation being accomplished by ultra-sonic sensors. The 3-DOF arm included a system for linear motion (i.e., up and down; back and forth) and rotation. In addition, the arm carried a ULV nozzle for spraying micro-doses toward individual plants or leaves. The locomotion part of the Cabbot was minimized in size, enabling it to turn corners easily and freely in approaching any plants near the rail. Detailed description of construction and operation of the Cabbot is beyond the scope of this study and will be reported elsewhere.

\section{Automatic sampling and pest counting equipment}

The sampling device on the Cabbot was composed of a sticky trap, a camera, and a multi-joint stand for positioning the sticky trap and camera (Fig. 1b). A commercially available yellow sticky trap (100 $\mathrm{mm} \times$ $150 \mathrm{~mm}$ ) with a 15-mm hardboard paper (white) margin (Green Agro Tech Co., Ltd. ${ }$, Gyeongsan-si, Korea) was installed on the multijoint stand of the robot. The trap was printed with green grids in 2 dimensions with $3 \mathrm{~cm}$ intervals to facilitate quantification of the collected insects. An air compressor was connected to the ULV spray nozzle and used to locally irritate pests on the leaves (Fig. 1b). The procedure used by the Cabbot to sample and count whiteflies was as follows: 1) the Cabbot was controlled to be located in front of each plant (interval between plants $=25 \mathrm{~cm}$ ) at a distance of approximately $10 \mathrm{~cm}$, and high-pressure air (50 PSI) from the nozzle was sprayed onto the plant leaves for a certain duration (e.g., 10 seconds) to agitate whiteflies near the spraying area; 2 ) after air spray, the Cabbot waited for a period (e.g., 180 seconds) for the agitated whiteflies to be collected onto the traps, and subsequently the trap image was captured by the camera; and 3 ) the whiteflies were identified by the image processing system and the number of adult whiteflies on the trap was counted.

A webcam (Logitech QuickCam C905®) with a 2-megapixel sensor (maximum resolution of $1600 \times 1200$ pixels) was used to record the
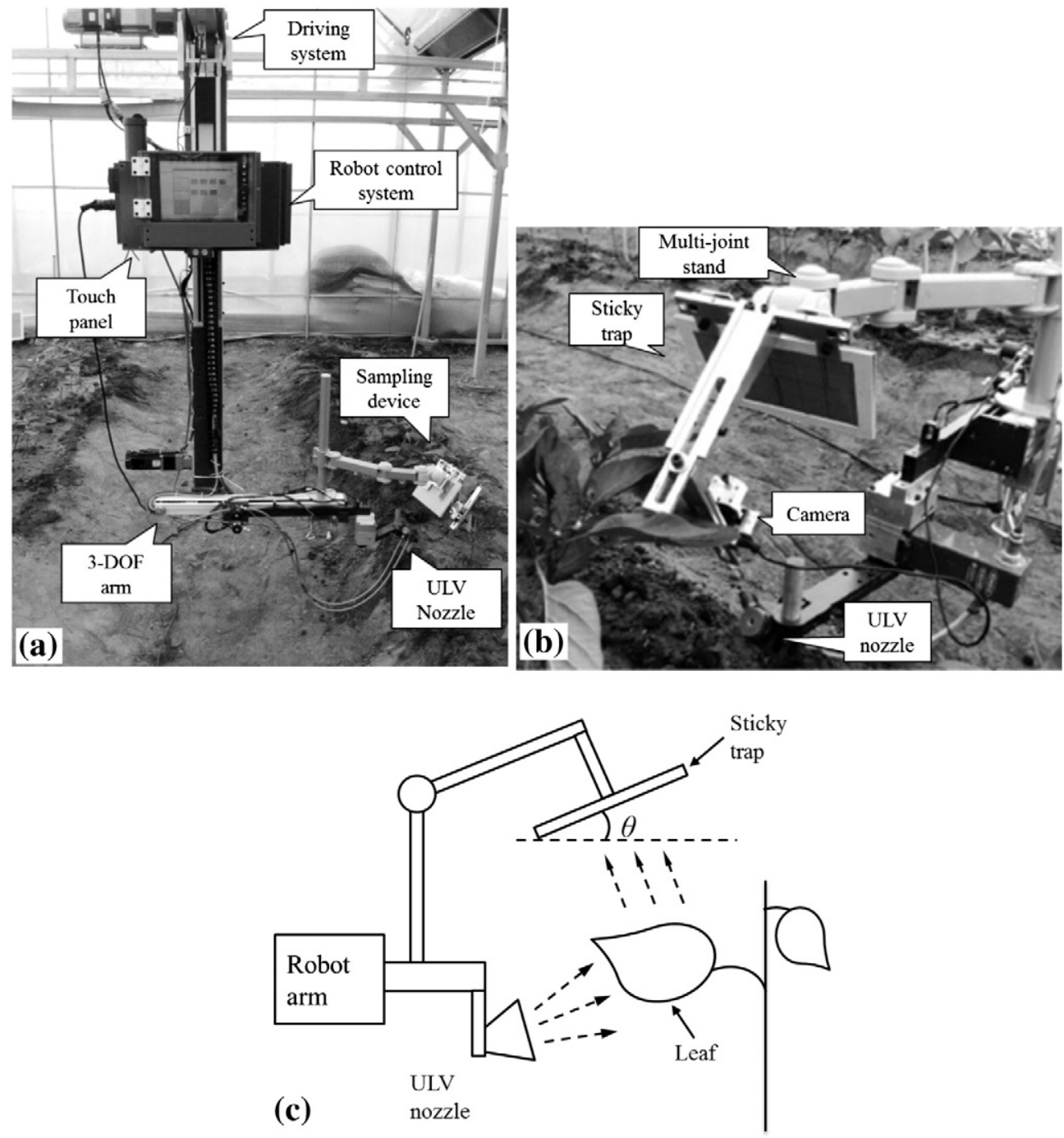

Fig. 1. Autonomous pest control robot (Cabbot). (a) Cabbot in operation, (b) sampling device, (c) schematic diagram of sticky trap with angle ( $\theta$ ) for collecting whiteflies. 
insect image. The camera was placed $100 \mathrm{~mm}$ ahead of the sticky trap to view insects attached to the trap (Fig. 1b). The number of adult whiteflies was counted by machine vision techniques. Recognition, counting, and recording whiteflies collected on the sticky trap on the Cabbot were conducted by a software developed according to Xia et al. (2012). Among numerous algorithms for detection of small sized insects (Cho et al., 2007; Solis Sánchez et al., 2009; Bechar et al., 2010; Kumar et al., 2010), multi-fractal analysis was employed to detect whitefly images from sticky trap images in our study since the method was outstanding in detection of small-sized pests against various noise produced on sticky traps under field conditions (Xia et al., 2012).

\section{Field experiments}

The Cabbot was deployed in a plastic greenhouse cultivating paprika at the Gyeongsangnam-do Agricultural Research and Extension Services (GNARES), Jinju, Korea. Soil was fertilized 2 weeks before the paprika was transplanted by common cultivation methods (Lee, 2001). Two experiment procedures were adopted to address effectiveness of the Cabot. First, we demonstrated that the Cabbot was efficient in collecting the insects, especially when population size was low in greenhouse. We coined the term collection efficiency in addition to sampling precision in this study. The collection efficiency was defined as the proportion of the number of samples that collected insects more than a predetermined number of pests to the total sample number. For instance, the number of samples collecting at least one individual is 2 whereas the total sample number is 10 ; the collection efficiency would be 0.2 for the sampled density equal to 1 or higher than 1 individual. And second, sampling precision represents the efficiency in collecting insects with different population-sizes (see Section Analysis of sampling precision).

For the first procedure for estimating collection efficiency and other related experiments, the Cabbot was tested with whiteflies infested on paprika (Capsicum annuum var. angulosum c.v. Special). Paprika was seeded on February 7, 2011 and transplanted into $10 \mathrm{~cm}$ diameter pots on March 9 and 10, 2011. There were 75 plants in each row, and three rows in the greenhouse. The paprika plants were irrigated regularly. Whiteflies were introduced to the young plants to lay eggs on April 6 and 14,2011 . To ensure infestation with a sufficient number of insects, the paprika plants on which eggs were deposited were transplanted to soil with an area of $220 \mathrm{~cm} \times 25 \mathrm{~cm}$ in the greenhouse $(17.2 \mathrm{~m} \times 19.4 \mathrm{~m})$ on May 6,2011 . When the whiteflies were counted from 15 leaves sample of the paprika on May 20, 2011, adults, larvae, and eggs were $3.5 \pm 5.6$, $27.1 \pm 15.4$, and $50.0 \pm 41.0$ per leaf in averages.

The experiments for measuring efficient trapping angle and repeated sampling were conducted from May 27 to 29, 2011. On May 27, 28, and 29 the weather conditions were rainy $\left(16.2{ }^{\circ} \mathrm{C}, 87.3 \mathrm{RH}\right)$, cloudy $\left(18.6{ }^{\circ} \mathrm{C}, 71.9 \mathrm{RH}\right)$, and sunny $\left(19.9{ }^{\circ} \mathrm{C}, 57.8 \mathrm{RH}\right)$, respectively. The collection of pest was conducted in early morning and late afternoon when the air temperature difference between the inside and outside of the greenhouse was minimized. The air temperature in the greenhouse measured with a mercury thermometer was $22.0 \pm 0.2$ and $23.5 \pm$ $0.3{ }^{\circ} \mathrm{C}$ at $11 \mathrm{AM}$ and $5 \mathrm{PM}$ on May 27, $25.3 \pm 1.3$ and $28.8 \pm 1.0^{\circ} \mathrm{C}$ at $9 \mathrm{AM}$ and $5 \mathrm{AM}$ on May 28, and $27.5 \pm 3.1,29.7 \pm 0.6{ }^{\circ} \mathrm{C}$ at $11 \mathrm{AM}$ and 5 PM on May 29, respectively. The plant height was approximately $34 \mathrm{~cm}$ (ranging $24 \mathrm{~cm}$ to $42 \mathrm{~cm}$ ) and had an average of 28 leaves per plant.

In order to find efficient angle of sampling, a test was conducted on isolated plants on the morning of May 27. The trap angle was tested at $0^{\circ}, 30^{\circ}, 60^{\circ}$ and $90^{\circ}$ to the ground for 300 seconds (Fig. 1c). The test was performed on isolated plants with 5 replications. The robot arm operation took 1 minute including arm movement for 50 seconds and air spraying to plants for 10 seconds. A separate test was conducted for collection of insects according to waiting time between 30 and 300 seconds after spraying for 10 seconds with five replications. Otherwise the methods were same to testing trap angles stated above.

Experiment for measuring collection efficiency was subsequently carried out from the afternoon of May 27 to the morning of May 29.
Each trial of collection by the Cabbot was conducted with one block of 7 plants. To prevent movement of whitefly adults between sampling areas, each block of plants was surrounded with the 3 side blocking walls with heights up to $100 \mathrm{~cm}$ using net fabrics. The remaining one side was open for sampling and handling the Cabbot. The experiments were conducted with five replications (blocks) in completely randomized design in greenhouse conditions. The sampling took 30 minutes for each block including robot motion, arm operation and waiting time ( 3 minutes) for collection. In the afternoon of May 29, repeated sampling with the Cabbot was further conducted sequentially on isolated plants with five repeats. Each repeat took 4 minutes consisting of arm operation ( 1 minute) and waiting for collection (3 minutes). All the experimental data were analyzed with SAS program ver. 9.2.

As the second procedure for estimating sampling precision (see Section Analysis of sampling precision) of the Cabbot, the sampling of insects was additionally performed in glasshouse with pairs of caged pots with singly potted plants comparing with conventional sticky trap sampling on October 7, 2011. A paprika cultivar of Cupra was seeded on August 7, 2011. The seedlings were transplanted two times in accordance with their growth. The second transplantation was conducted in the $10 \mathrm{~cm} \times 10 \mathrm{~cm} \times 10 \mathrm{~cm}$ glass-wool cubes, and then watered with nutrient solution. During sampling, the weather condition was sunny in the Jinju area $\left(14.0^{\circ} \mathrm{C}, 62.8 \mathrm{RH}\right)$. Temperature and humidity, however, in the greenhouse were not measured due to facility limitation at this time. Considering the weather condition in the other glasshouses in the same research station, GNARES, was $21.3(13.4-31.4){ }^{\circ} \mathrm{C}$ and 69.2 (45-83) RH, the temperature and relative humidity could be assumed approximately in the range of $23-26{ }^{\circ} \mathrm{C}$ and $40-60 \mathrm{RH}$ in the greenhouse during the experiment of sampling precision.

Sampling precision by conventional sticky traps and the Cabbot was tested for comparison (Fig. 2). The cage size was set to $80 \mathrm{~cm} \times 80 \mathrm{~cm} \times 80 \mathrm{~cm}$ to allow sufficient space for the paprika plant, which was $40-50 \mathrm{~cm}$ tall (Fig. 2). The cage consisted of wooden bars enclosed by fabric nets, and one side was opened for sampling by the Cabbot arm (Fig. 2a). Plants were manually infested with 8, 16, 32, 64 and 128 whiteflies per plant.

For the Cabbot sampling, the sticky trap was placed with the angle according to the "measuring efficient trapping angle" as stated above (Fig. 2a). The nozzle sprayed high pressure air to cover the whole size of the plant. The total sampling time by the Cabbot was 3 minutes, consisting of 1 minute of arm operation followed by 2 minutes of collection. The sticky traps for conventional sampling were vertically placed $10 \mathrm{~cm}$ over the canopy within the cage (Fig. 2b). The sampling was conducted for 3 minutes. Five replications were observed for both the Cabbot and sticky trap samplings for each level of pest density in the cage.

\section{Analysis of sampling precision}

The reliability of the total density estimation by the Cabbot and the sticky trap (Pedigo and Buntin, 1994) was evaluated by precision of sequential sampling (Kim et al., 2001; Park et al., 2001; Baek et al., 2009; Venter et al., 2009; Kim and Lim, 2011). The sampling precision could be expressed as a parameter addressing the reliability of collecting insects across different population sizes in sampling area and could be expressed as, $D$ (Pedigo and Buntin, 1994):

$D=\frac{\mathrm{SE}}{m}=\frac{\sqrt{s^{2} / n}}{m}$,

where $s^{2}$ and $m$ indicate the variance and mean of the sampled insects respectively, and $n$ is the sample size. The smaller value of $D$ presents the higher precision of sequential sampling. An empirical model (Green, 1970) also efficiently estimates the precision of sequential 

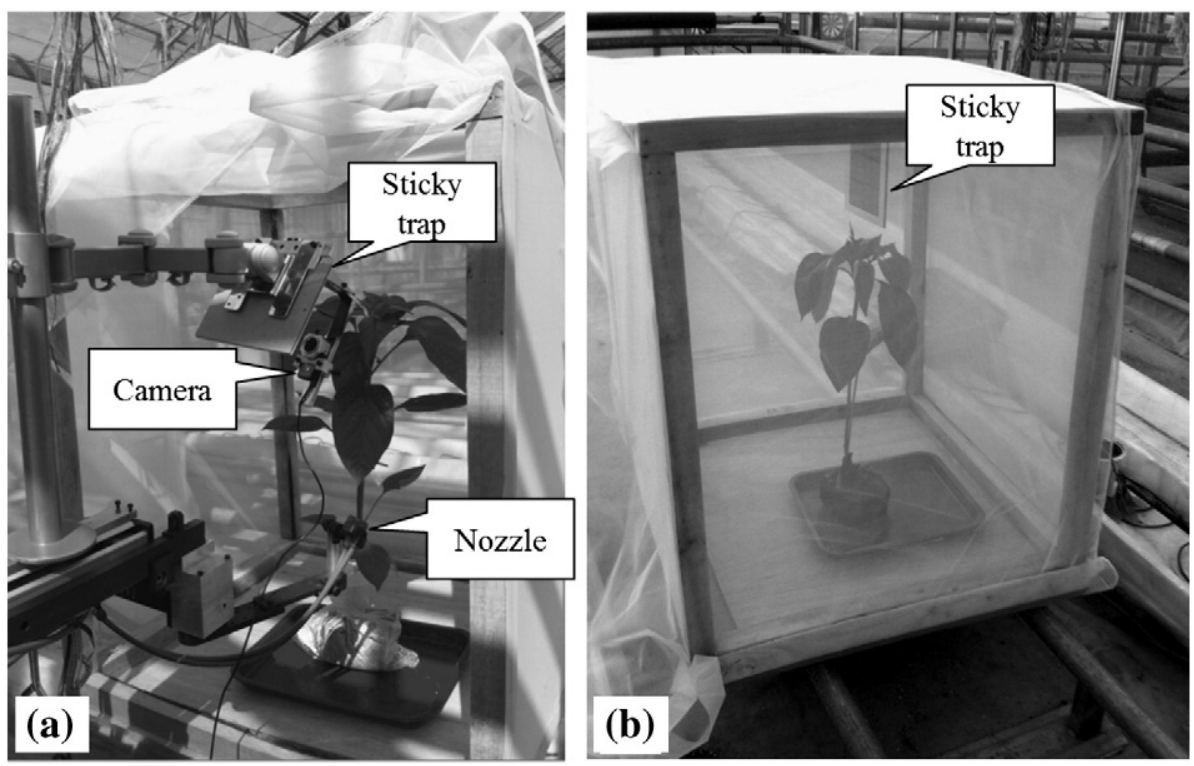

Fig. 2. Sampling of whiteflies within the caged plants, (a) the Cabbot, and (b) sticky trap.

sampling based on Taylor's power law (Taylor, 1961; Pedigo and Buntin, 1994):

$\log s^{2}=\log a+b \log m$

where the slope, $b$, measures the aggregation and the intercept, $\log a$, is a scaling factor related to the environment. The coefficients of Green's model were obtained from Taylor's power law relationship to determine the sampling stop-line:

$\ln T_{n}=\frac{\ln \left(D_{0}^{2} / a\right)}{b-2}+\frac{b-1}{b-2} \ln n$,

where $T_{n}$ is the cumulative number of sampled pests, and $D_{0}$ is the fixed level of precision in terms of $D$. In this study, $D_{0}$ was set to 0.20 as a reference for the evaluation of the sampling precision of the Cabbot and the conventional sticky trap.

\section{Results and discussion}

\section{Collection performance}

The sampling was initially conducted by setting the sticky traps on the Cabbot at a range of various angles $\left(0^{\circ}\right.$ to $\left.90^{\circ}\right)$ to the ground (Fig. 1c) in order to find which angle of the traps would be most suitable to collect adult whiteflies. The maximum number of captured whiteflies after local disturbance of the plants occurred at $90^{\circ}$ to the ground (i.e., perpendicular to the long axis of leaf) $(d f=3, F=6.00$, Tukey HSD $P<0.01$ ) (Fig. 3).

We further tested how quickly the Cabbot could collect the insects after agitation by air spraying. As shown in Fig. 4, the trap on the Cabbot collected insects extremely quickly near the sampling area and approximately $60 \%$ of the whiteflies were sampled immediately within $30 \mathrm{sec}-$ onds after air spray $(d f=9, F=18.62$, Tukey HSD $P<0.01)$. The additional sampling of collection decreased rapidly after 30 seconds, though a short peak was observed at 150 seconds after spraying. Approximately $90 \%$ of the insects collected on the trap were captured within 180 seconds. Since most of adult whiteflies were collected within 3 minutes under experimental conditions conducted in this study, we investigated the collection efficiency for 3 minutes and compared the results with the conventional sticky traps across different levels of population size for the same duration (see Section Field experiments).
It is worth noting that the Cabbot was efficient in collecting insects under low population size. Fig. 5 shows the number of whitefly adults collected by the Cabbot across different population sizes (up to 250 individuals per plant) under greenhouse conditions when the sampling was conducted for 30 minutes per block (see Section Field experiments). As the population size increased, the number of insects sampled increased as expected. At low densities when the population size was less than 10 individuals per plant, insects were still consistently collected remarkably. In the low range of population size ( $\leq 16$ individuals per plant), however, the increase in the number of collected insects corresponding to population size could not be clearly observed due to extremely low level of population size. Higher frequencies of samples were observed at low densities although the number of insects collected per plant was small.

Histograms were produced to show the frequency of the samples ( $x$ axis) according to different number of pests per sample ( $y$ axis) from small, medium and large population sizes (Fig. 6). The bars in the histogram shown in Fig. 6 were fitted to the Poisson distributions (dashed line) in low and medium population sizes, showing the parameter, $\lambda$, in the range of $0.278-1.961$ (Figs. $6 a$ and b). The fitness was relatively low at high population size (Fig. 6c). The high collection efficiency at low densities could make a significant contribution to early warning systems, especially when some species of whiteflies serve as vectors for plant viral disease, such as the Tomato Yellow Leaf Curl Virus (TYLCV) in tomatoes (Cohen and Antignus, 1994).

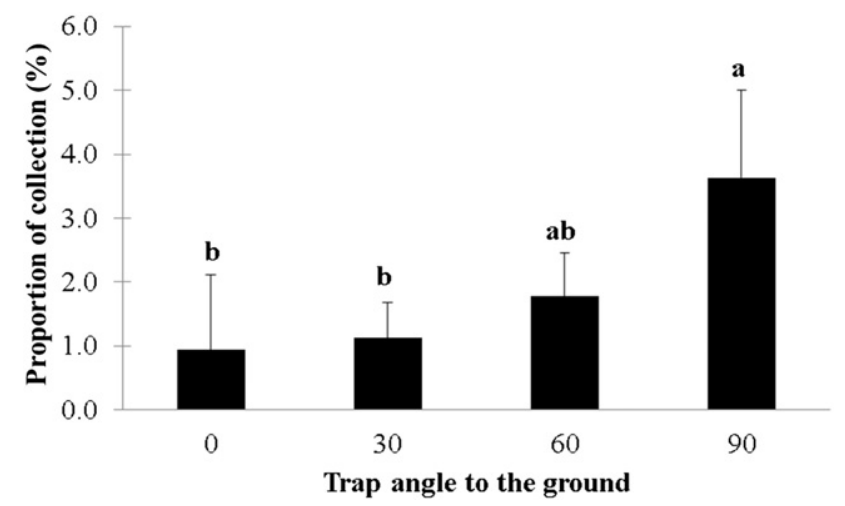

Fig. 3. Proportion of collection by the Cabbot across different angles of sticky trap to the ground. Different alphabets indicate statistical significance $(d f=3, F=6.00$, Tukey HSD $P<0.01)$. 


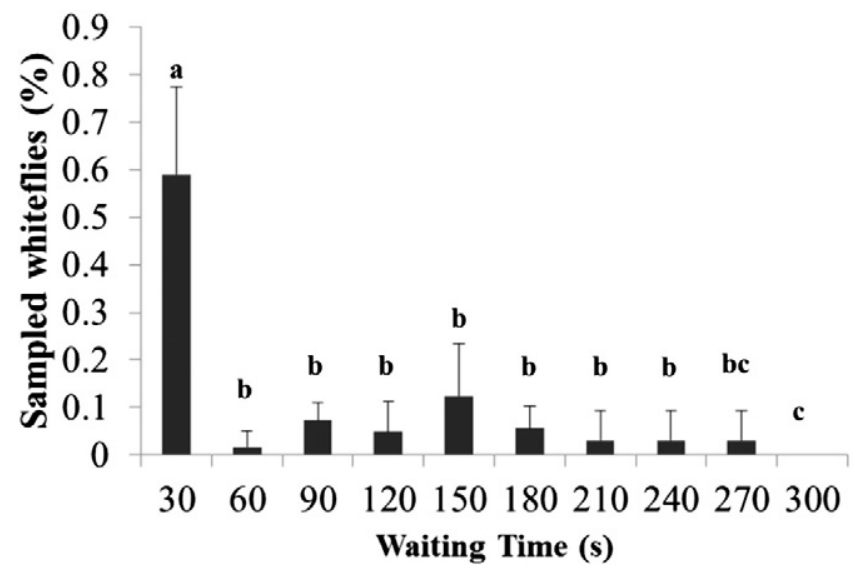

Fig. 4. Whiteflies sampled by the Cabbot within 300 seconds after air spray. Different alphabets indicating statistical significance according to multiple comparison $(d f=9, F=18.62$, Tukey HSD $P<0.01)$.

Collection efficiency could be expressed from Fig. 6 (solid line) as the proportions of samples that collected more than a predetermined number, $n$, of pests in accumulation (i.e., from left to right in $x$ axis in Fig. 6) to total number of samples. Accumulation of the proportions up to $n$ individuals in Fig. 6 indicates collection efficiency for the sampled density $n$ per trap or higher number of individuals per trap. When there was a low population size ( $\leq 16$ individuals per plant, or $<0.5$ whitefly per leaf), collection efficiency for the sample density with one individual or higher number of individuals was 0.27 of the total samples (Fig. 6a). When population size was intermediate (17 to 80 individuals per plant, or 0.5-3.0 whiteflies per leaf), approximately 0.66 of the samples contained at least one individual (Fig. 6b). At high population densities ( $>80$ individuals, or 3-9 whiteflies per leaf in this experiment), collection efficiency was 0.82 (Fig. 6c).

It is worth noting that reasonably high collection efficiency under the condition of low population size would be efficient in practice of pest control under greenhouse conditions. Early warning would be extremely important for fruit and vegetables in greenhouse for practical purposes. The accurate estimation of pest densities by sampling (i.e., high sampling efficiency) would be necessary to estimate overall population size, but measurement of population size in high levels may play a less important role considering urgency of early warning from practical aspects. Since the surveillance is conducted continuously by the managers and growers during cultivation processes in greenhouse, the pest with high population size would be detected anyway by humans before the populations are strongly built up in field conditions. However, early detection of a small number of pests under low population size would not be easily accomplished by human efforts. In this regard, the continuous survey by the robot with high collection efficiency at low population size would be advantageous and feasible in early detection of pests in field conditions. Consequently the issue of early warning would be urgent in greenhouse conditions where economically high-valued crops are cultivated and especially if the viral diseases are transmitted by vector borne pests.

\section{Sampling precision}

To measure the sampling precision of the Cabbot, adult whiteflies were collected from caged pots of paprika plants in comparison with the conventional sticky trap (Fig. 2) across different levels of population size (Fig. 7). A linear regression was observed for the number of insects collected per plant with respect to the increase in pest population size. The slope was consistently higher for the Cabbot than the conventional $\operatorname{trap}\left(R^{2}=0.986\right.$ for Cabbot and $R^{2}=0.9511$ for conventional sticky trap; $d f=56, \mathrm{t}=6.0742$, Tukey HSD $P<0.01$ ).

Based on sampled data across different population sizes, the sampling precision $(D=0.16)$ obtained by Eq. ( 1 ) was higher for the Cabbot than the sticky trap $(D=0.19)$. The slopes of linear regressions of the Cabbot and the conventional trap sampling were statistically significant according to Zar (1999) $(P<0.01)$. Overall, the sampling precision implied that the Cabbot samples adult whiteflies more efficiently than the conventional sticky trap regarding local and short-time sampling effects.

In Fig. 8, the stop-lines for sampling are presented with a fixed precision level $D_{0}=0.20$ based on Eqs. (2) and (3). In this figure, the cumulative number of whitefly adults $\left(T_{n}\right)$ collected by the Cabbot and the sticky trap are plotted along with the stop-lines. Twenty samples were required to achieve precise sampling for the Cabbot, while 30 samples were needed for the conventional sticky traps. For the Cabbot sampling, the parameters were estimated as $a=1.06$ and $b=1.43$ according to Eqs. (2) and (3). When $1<b<2$, the expected cumulative number of pests showed a negative slope $(\log -\log )$, indicating that the distribution of the pests was aggregated (Taylor, 1961; Kim et al., 2001). However, when sampling was conducted using the conventional sticky trap, both parameters decreased with $a=0.89$ and $b=0.6$. The stop-line showed a gradually increasing curve as sample size, $n$, increased (Fig. 8), which was not in accordance with the curve used for estimating samples collected by the Cabbot. According to previous reports the conventional sticky traps over the longterm (one or several weeks) resulted in negative slopes with $b$ values between 1 and 2 (Kim et al., 2001; Kim and Lim, 2011). In this study, the $b$ value using the conventional trap showed the value less than 1.0.

Only 3 minutes, however, was allowed for collecting whiteflies for the conventional sticky traps in this study. Considering the conventional sticky traps are usually placed in the greenhouse for a long time for

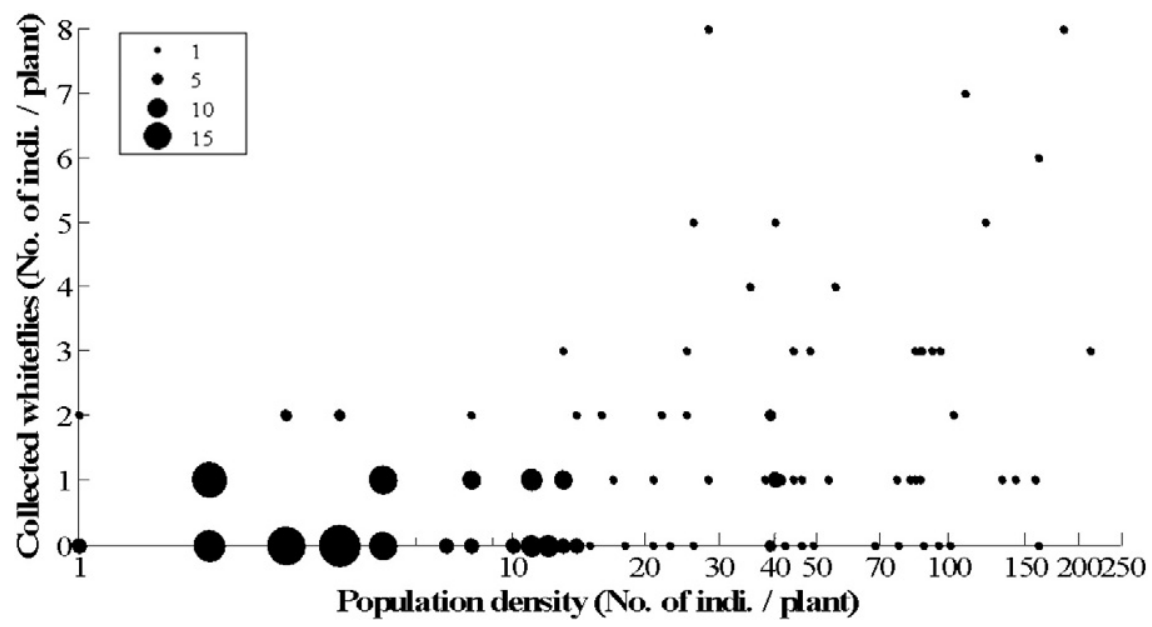

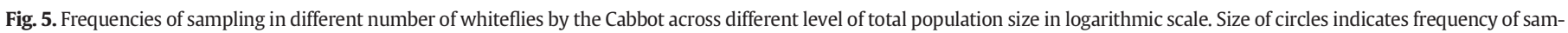
ples with the collected number of whiteflies per plant. 

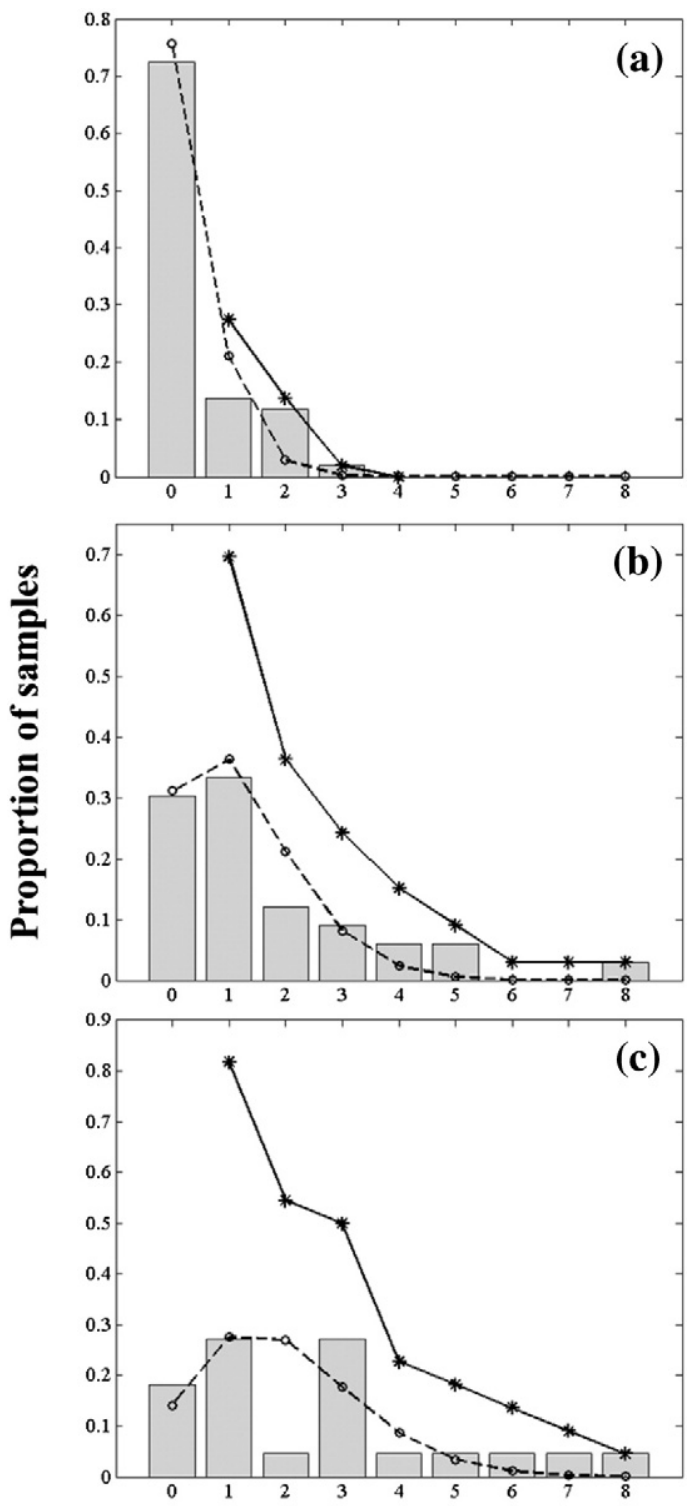

No. of individuals

Fig. 6. Histogram of proportion of samples across different number of sampled individuals fitting the Poisson distribution (dashed line with "o" marks) by goodness of fitness test, and the accumulated proportion of samples (solid line with "** marks) indicating collection efficiency when individuals sampled per trap is equal to or higher than $n$. (a) Population size $\leq 16, \lambda=0.278, R^{2}=0.9968$, (b) $16<$ population size $\leq 80, \lambda=$ $1.164, R^{2}=0.8834$, and (c) population size $>80, \lambda=1.961, R^{2}=0.4861$.

survey, it would be more feasible to check sampling efficiency of conventional sticky traps for a long time. The long-term sampling efficiency, however, was not performed since this study was focused on demonstrating the local and fast effects of sampling by the robot as stated above. The continuous recording and evaluation of sampling by the robot for a long time survey would require an extra scope of research resources. A future study, however, would be required with a large number of samples for a long period to enable comparison with the sampling efficiency of the conventional sticky trap and to report the overall efficiency of pest detection during the whole process of cultivation.

\section{Repeated sampling}

Since the Cabbot sampling could be accomplished in a short time, the sequence of agitation-collection-recognition-counting could be repeated. The repeated sampling was further conducted with the Cabbot

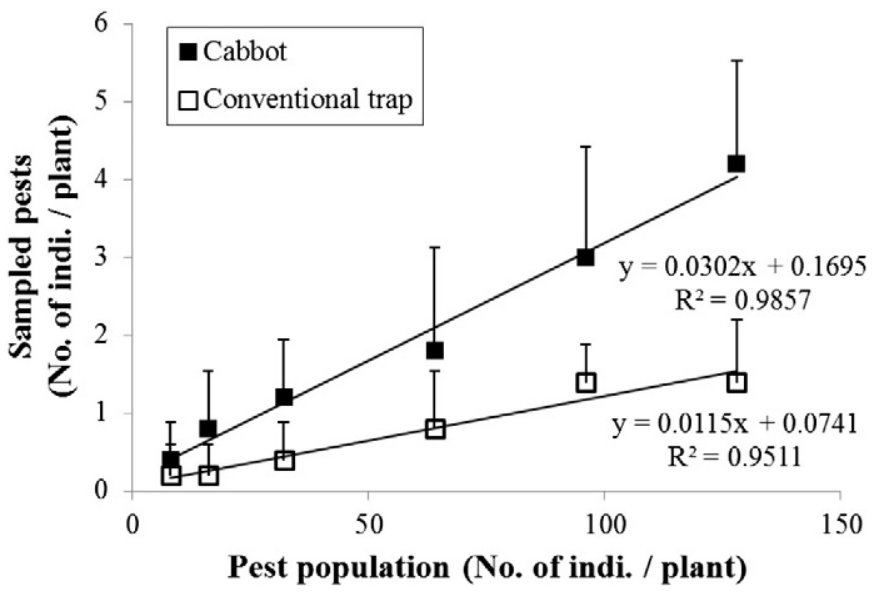

Fig. 7. Sampling of adult whiteflies in caged pots by the Cabbot and conventional sticky trap (difference in two slopes: $t=6.072, d f=56$, Tukey HSD $P<0.01$ ).

five times sequentially for a total of 20 minutes attraction, during which pests were collected continuously.

Approximately $30 \%$ of the total population (292.8 individuals) was captured after 5 trials of sampling (Fig. 9) (see Section Field experiments). The densities of whiteflies remaining in the plants decreased continuously with repetition of sampling, with the number of whiteflies (100.8 individuals) collected during the 5th collection being 6.2 times higher than the number collected during the first sampling (16.2 individuals) (Fig. 9). It is worth noting that the Cabbot collected insects consistently, with 14.0-36.4 individuals being captured per plant per trial.

These findings imply that the impact of wind disturbance by the Cabbot was local, and the insects could be continuously collected by the robot under greenhouse conditions. According to Eq. (1), the precision of repeated sampling $(D)$ was as high as 0.09 , indicating that repeated sampling contributed to a substantial increase in the sampling precision.

The populations remaining on the plants may further decrease to a minimal level with additional sampling, although only five samplings were conducted in this study. Further sampling with more repetition is needed to identify the minimum population size that can be sampled. Additionally, the continuous collection of insects would provide useful information for determination of the level of eradication from the robot collection under field conditions. The extensive repetitive sampling would also be useful for detecting early invasion by pests. However, such a study would require extensive research facilities and resources to evaluate the precise eradication level or detection of the pest insects at extremely low densities. Further studies may be required

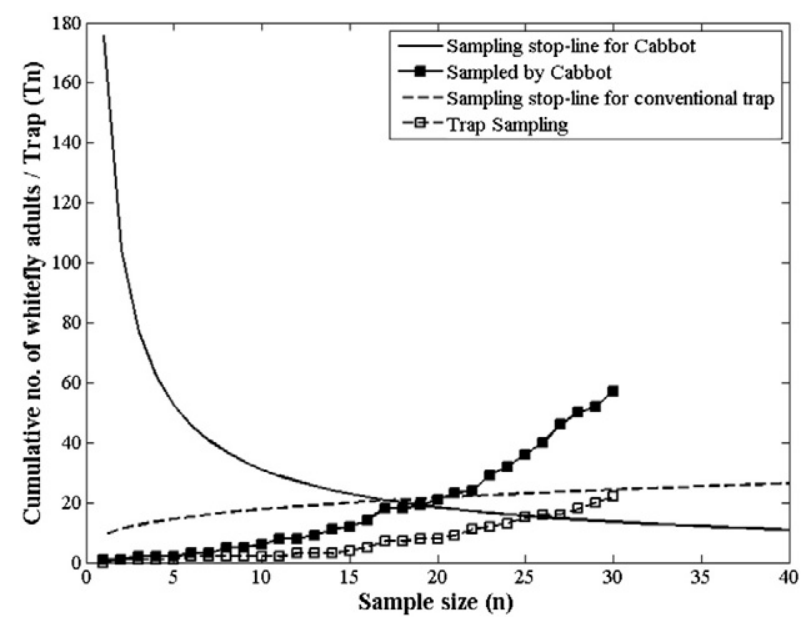

Fig. 8. Sequential sampling stop-lines for estimating the density of whiteflies by the Cabbot and the conventional trap at precision level $D_{0}=0.20$. 


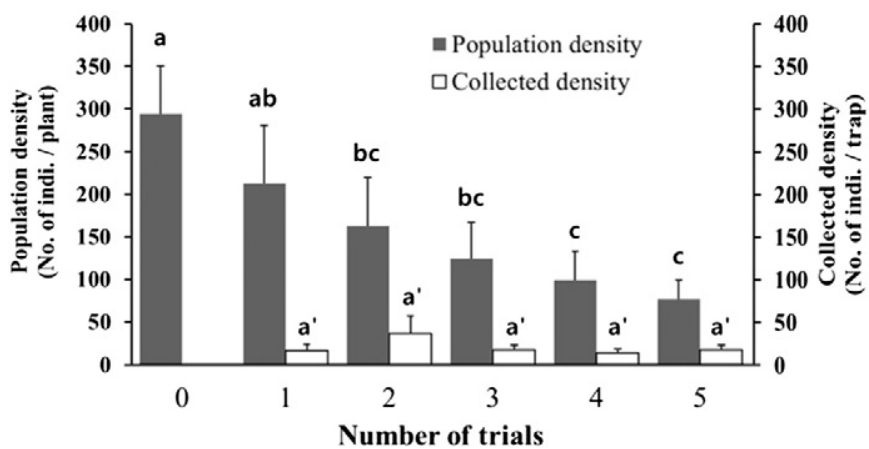

Fig. 9. Collection of the whiteflies on the traps with the repeated sampling (1-minute arm operation followed by 3-minute collection per trial). (Population density, $d f=24$; collected density, $d f=20$; Tukey HSD, $P=0.05$ ). Different alphabets in the figure indicate statistical difference.

to investigate the optimized repetition number, collection by wind spray, sampling at minimum densities, etc. Considering that the robot was originally designed to operate continuously, the repeated sampling by the robot would be a strong point for ensuring low pest population management and early detection of invasion by pests. In summary, short-term, repeated sampling by the Cabbot appeared to show the potential for estimation of population densities and sampling of small population size especially when the pests carry vector borne diseases (Figs. 7-9).

It would be desirable to apply the robot for sampling of other species commonly found in greenhouses, such as thrips and mites. For application to western flower thrips, Franklinella occidentalis (Pergande), for instance, it may be necessary to have higher visibility for collection because this insect is thin and much smaller than whitefly. Moreover, use of the system for mites such as Polypagotarsonemus latus (Banks), which damage the growing point of paprika shoots, should be investigated (Zhu and Zhang, 2011).

Additional consideration should also be given to recognition of life stages other than adults for detection. The air disruption is only effective on adult insects; therefore, further development of hardware and software for collecting and recognizing different life stages of insects would be necessary in the future.

\section{Conclusion}

An automatic sampling device operated by a robot (Cabbot) was found to successfully estimate population density in situ. A novel mechanism of pest collection including local agitation of whiteflies followed by automatic pattern detection of insects on the traps is proposed to achieve higher sampling precision when compared with the conventional sticky traps under greenhouse conditions regarding local, shortterm sampling events. The Cabbot also efficiently collected pests at low population densities and was suitable for repeated sampling; accordingly, the developed system has the potential for use in early warning during greenhouse cultivation under the conditions of low population size.

\section{Acknowledgments}

We appreciate Craig and Katie Lawrence for reading the initial draft. We thank Mr. Jeong, Jeong-min for cultivating paprika plants in the greenhouse. We are also indebted to colleagues of the first author, Drs. Tae-Sung Kim, Jin-Hyeuk Kwon, Heung-Su Lee, and Won-Doo Song, for their support. This study was supported by the Korea Institute of Planning and Evaluation for Technology of Food, Agriculture, Forestry, and Fisheries under grant number 108929033HD120.

\section{References}

Arbogast, R.T., Kendra, P.E., Weaver, D.K., Shuman, D., 2000. Insect infestation of stored oats in Florida and field evaluation of device for counting insects electronically. J. Econ. Entomol. 93, 1035-1044.

Baek, S., Cho, K., Song, Y.H., Lee, J.H., 2009. Sampling plans for estimating pepper fruit damage levels by Oriental tobacco budworm, Helicoverpa assulta (Guenee), in hot pepper fields. J. Asia Pac. Entomol. 12, 175-178.

Bechar, I., Moisan, S., Thonnat, M., Bremond, F., 2010. On-line video recognition and counting of harmful insects. The 20th International Conference on Pattern Recognition (ICPR), 23-26 Aug. 2010, pp. 4068-4071.

Brosnan, T., Sun, D., 2002. Inspection and grading of agricultural and food products by computer vision systems-a review. Comput. Electron. Agric. 36, 193-213.

Cho, J., Choi, J., Qiao, M., Ji, C., Kim, H., Uhm, K., Chon, T.S., 2007. Automatic identification of whiteflies, aphids and thrips in greenhouse based on image analysis. Int. J. Math. Comput. Simul. 1, 46-53.

Cohen, S., Antignus, Y., 1994. Tomato yellow leaf curl virus (TYLCV), a whitefly-borne gemini virus of tomatoes. Adv. Dis. Vector Res. 10, 259-288.

Flinn, P.W., Opit, G.P., Throne, J.E., 2009. Predicting stored grain insect population densities using an electronic probe trap. J. Econ. Entomol. 102, 1696-1704.

Green, R.H., 1970. On fixed precision sequential sampling. Res. Popul. Ecol. 12, 249-251.

Kim, S., Lim, U.T., 2011. Evaluation of a modified sticky card to attract Bemisia tabaci (Hemiptera: Aleyrodidae) and a behavioral study on their visual response. Crop. Prot. 30, 508-511

Kim, J.K., Park, J.J., Park, H., Cho, K., 2001. Unbiased estimation of greenhouse whitefly, Trialeurodes vaporariorum, mean density using yellow sticky trap in cherry tomato greenhouse. Entomol. Experiment. Appl. 100, 235-243.

Kitamura, S., Oka, K., 2005. Recognition and cutting system of sweet pepper for picking robot in greenhouse horticulture, mechatronics and automation. IEEE International Conference on Mechatronics and Automation, 29 July-1 Aug. 2005, pp. 1807-1812.

Kumar, R., Martin, V., Moisan, S., 2010. Robust insect classification applied to real time greenhouse infestation monitoring. Proceedings of the 20th International Conference on Pattern Recognition on Visual Observation and Analysis of Animal and Insect Behavior Workshop, 22 Aug. 2010, pp. 1-4.

Lee, J.W., 2001. Present condition of paprika cultivation and its prospects for export. Kor. Res. Soc. Protected Hort. 14, 36-41.

Ota, T., Bontsema, J., Hayashi, S., Kubota, K., van Henten, E.J., van Os, E.A., Ajiki, K., 2007. Development of a cucumber leaf picking device for greenhouse production. Biosyst. Eng. 98, 381-390.

Park, J.J., Kim, J.K., Park, H., Cho, K., 2001. Development of time-efficient method for estimating aphids density using yellow sticky traps in cucumber greenhouses. J. Asia Pac. Entomol. 4, 143-148.

Pedigo, L.P., Buntin, G.D., 1994. Handbook of Sampling Methods for Arthropods in Agriculture. CRC Press, Florida.

Sammons, P.J., Furukawa, T., Bulgin, A., 2005. Autonomous pesticide spraying robot for use in a greenhouse. Australasian Conference on Robotics Automation. Dec. 2005, pp. 1-9.

Slaughter, D.C., Giles, D.K., Downey, D., 2008. Autonomous robotic weed control systems: a review. Comput. Electron. Agric. 61, 63-78.

Solis Sánchez, L., García Escalante, J., Castañeda Miranda, R., Torres Pacheco, I., Guevara González, R., 2009. Machine vision algorithm for whiteflies (Bemisia tabaci Genn.) scouting under greenhouse environment. J. Appl. Entomol. 133, 546-552.

Taylor, L.R., 1961. Aggregation, variance and mean. Nature 189, 732-735.

van Henten, E.J., van Tuijl, B.A.J., Hemming, J., Kornet, J.G., Bontsema, J., van Os, E.A., 2003. Field test of an autonomous cucumber picking robot. Biosyst. Eng. 86, 305-313.

Venter, G.J., Labuschagne, K., Hermanides, K.G., Boikanyo, S.N.B., Majatladi, D.M., Morey, L., 2009. Comparison of the efficiency of five suction light traps under field conditions in South Africa for the collection of Culicoides species. Vet. Parasitol. 166, 299-307.

Xia, C., Lee, J.M., Li, Y., Chung, B.K., Chon, T.S., 2012. In situ detection of small-size insect pests sampled on traps using multifractal analysis. Opt. Eng. 51, 027001.

Xia, C., Lee, J.M., Li, Y., Song, Y.H., Chung, B.K., Chon, T.S., 2013. Plant leaf detection using modified active shape models. Biosyst. Eng. 116, 23-35.

Yang, L., Dickinson, J., Wu, Q.M.J., Lang, S., 2007. A fruit recognition method for automatic harvesting. 14th International Conference on Mechatronics and Machine Vision in Practice. 4-6 Dec. 2007, pp. 152-157.

Zar, J.H., 1999. Biostatistical Analysis. Prentice Hall, New Jersey.

Zhu, L.Q., Zhang, Z., 2011. Insect recognition based on integrated region matching and dual tree complex wavelet transform. J. Zhejiang Univ. Sci. C (Comput. Electron.) $12,44-53$. 